\section{A REMARKABLE CASE OF PROBABLY CANCEROUS DISEASE.}

BY CHARLES WILLIAMS, L.R.C.P., L.R.C.S., L.S.A.

IN October, $1885, \mathrm{G} . \mathrm{T} \longrightarrow$ - a sailor, aged thirty-two years, came to ask my opinion about a wart on his lower lip, in size equal to a small Barcelona nut. He told me that two or three years before he had had a wart in exactly the same place, but that this had been tied, burnt with caustic, and apparently quite got rid of. This new wart, he said, occupied exactly the same situation as the old one, and had been gradually getting larger for some two or three months. I told him that it looked very suspicious, and that I should like to see it again in a week or two's time. As, however, he was leaving for sea the next day this could not be; so, after warning him of its being likely to prove of a cancerous nature, I extracted from him a promise that if it increased in size at all during the next few weeks he would show it to a doctor at the first port his vessel stopped at.

I saw nothing more of the man from this time till March, 1886, when he returned from sea, and again came to my surrery. I was now quite alarmed at the size the wart had attained, as well as the unmistakable character of epithelioma it had put on; therefore, within a few days of his return, I prevailed upon him to allow me to thoroughly excise it. At this operation I was assisted by a neighbouring medical man, and he quite agreed with ine as to its indubitably malignant character. This being the case, I was careful to cut quite free of the disease, and, as the ulcerated and indurated mass occupied fully half the surface of the lip, I really excised nearly all of the lower lip. The operation was done with the help of cocaine by the ordinary $\mathrm{V}$-shaped incision, and strong hare-lip pins inserted. He made a very rapid recovery, the lip joined nicely, and nine days afterwards he left for sea again. All went on well, and the reports from him were most encouraging, till January 1887, when, on feeling his throat, he found that a swelling, the shape of an egg, was beginning to make its appearance underneath the chin, and this continued to enlarge and spread to such an extent that when he stood upright the bottom of it touched the top of the sternum. He said that in appearance it still retained the oval shape, and looked exactly like a large egg-shaped bladder. $\mathrm{He}$ dirl nothing to it at all, and, although he suffered very great pain, it was six weeks before he saw a doctor. At the end of this time his vessel touched at Liverpool, and there he went to a doctor's surgery, and had the advantage of seeing two medical men together. Afier examining the swelling they lanced it, and the man stated that directly they had done so a pint of dark-brown matter escaped. They saw the cicatrix on his lip, and strongly advised him to go into a Liverpool hospital; they also said they were moing to test the matter which came out; but as he was determined to return home he left without either going to the hospital or seeing these surgeons again. It was some weeks, however, before he reached home, as his vessel was going from place to place, loading and discharging cargoes on the way. During all this time ke was poulticing with linseed meal as directed by the Liverpool surgeons, and the wound was discharging constantly and copiously.

This was its condition, then, on May 5th 1888, when he arrived home and came to show himself to me at my surgery: a large gaping wound, with well-marked imduration around, and offensive matter coming in large quantities from the opening. As I had not seen the patient since the removal of the lip, which was more than towelve months previously, I feared that I read in this the failure of the operation, that, through having been left too long, the glands of the neck had become infected, and that this was the explanation of his trouble. The history of the onset of this swelling, however, being rather unlike cancer, I told him, in answer to his anxious inquiry, that I was in doubt about its true nature, and that in order to settle it he had better adopt the advice of the Liverpool surgeons and go to a large hospital. He fell in with ny suggestion, and on May 14th last presented himself for admission at the South Devon and East Cornwall Hospital at Plymouth On the Thursday the visiting surgeons saw it together, and, although they prober it and examined it carefully, he was not able to glean from them what they thought of it. The following Friday he was brought down to the operating theatre, laid on his back on the table, the surgical staff were there ready to operate, and the inhaler was just about to be put to his mouth, when one of the surgeons called attention to the cicatrix on his lip. They asked him about it, a short consultation followed, and the next moment they said "Take him out." They afterwards came into the ward and told him that he must either have the whole of his lower jaw taken away or else nothing at all, and that, as this operation was such a formidable and dangerous one, and would more than probably prove fatal, their advice to him was to let it alone. He decided to take their advice, and came home prepared to die. This, then, was the story of what happened at the hospital as related by him to me on his return, and, seeing that I have often questioned him about it and he has always adhered to his original statements, the facts are probably just as he represented. At all events, on May 24th, he came again to my surgery, having only been discharged that day from the hospital; and as the place looked much worse now even than it did when he went there, and although the poulticing had been discontinued at the hospital and the wound filled with cottonwool saturated with carbolic acid lotion, the discharge was as offensive in smell and as large in quantity as it was before he left to go there. I now told him for the first time that the balance of probability was in favour of cancer, for, although it did not commence in the usual way, it had latterly come to look very much like it. I cheered him up, however, by telling him there was still a slight doubt, and that I had a genuine doubt is evident from the fact that the following week an effort was made to get him into the Cancer Hospital in London; and, on filling up the form giving particulars of the case, I stated there, I believe, that the diagnosis was not certain. However, as there was no vacancy, he was told that he could not be admitted, and from that day to this he has been under my personal supervision and care; and it is, indeed, the progress of the case from this point onwards that makes it more peculiar than ever.

On May 24th last, then, the man came home, and the wound was dusted with iodotorm and carbolic lotion applied. It gradually, however, became worse, and, although on this day and in the following week he came to the surgery to have it dressed, at the end of this time the wound had got so large, and the copious discharge which was incessantly coming from it had so weakened him, that from this time onwards I went to his own home to dress it. At the end of another fortnight his condition was alarming. His face was red, hot, and swollen; the difficulty in swallowing (which up to this point had not been very marked) became worse, and for the first time his breathing was embarrassed. His breathing, indeed, became so bad after a day or two that it could be heard all over the house; and on the night of June 4th, not only was it quick and laboured, but every now and then he would have a spasm of the glottis, which made him turn black in the face and struggle for breath. I visited him two or three times during the evening, and suggested the performance of tracheotomy, saying that it might be the means of prolonging life, which would otherwise be every instant in the greatest peril. On learning that the relief would only be temporary, although I had my instruments ready, and during a paroxysm which seemed as if it would almost certainly suffocate him I strongly advised them not to let him die, they refused to forego their objection, and so I left for the night, never expecting to see him alive again. His father, mother, brothers, and sisters were all round him watching, as they thought, his life ebbing away; whilst, as I went out, his mother thanked me for all my kindness to him, and said, with tears in her eyes, that there was nothing now for her to do but to follow bim to his grave.

The next morning I was called out of bed early to another case, and went to the house expecting to hear how he died. Judge of my surprise, therefore, to find that he was not only living but that a distinct improvement had set in. The breathing, which had been so loud and hurried, was now quiet and natural, whilst the alarming spasms of the glottis, which had nearly destroyed him the previous night, no longer harassed him. I learned that, soon after I left the house the previous evening, more than once they had thought he had "gone," and all concerned agreed in the opinion that the change which had taken place in his condition was nothing less than a miracle. To be brief, then, he gradually improved; the breathing became quite 
natural, the swallowing easier, and his speech plainer; whilst his tongue, which had been glued down to the floor of his mouth, once more became free. His strength, too, returned, and at the end of a comple of weeks he was able to get downstairs, and shortly afterwards was well enough to go out of doors.

This was his condition in the beginning of July, when, one day, when lie was out for a walk, copious bleeding came on, which was repeated every two or three days during the whole of the month. This so weakened him that he took to his bed. He was watched carefully day and night, and it appeared quite certain that if he had another attack he would not survive it. Indeed, we feared every day would be his last. Just as he appeared, however, to be in extremis from the loss of blood, and the pain was so severe that he had at last to take as nuch as two grains of morphia (sometimes twice or thrice repeated in a nicrht before he could get ease), or else have hypodermic injections of a grain at a time, this became subdued, and the discharge lessened in quantity as well as became less offensive in smell (at last, indeed, it ceased altogether, and there was no smell from the wound at all). Moreover, the granulations assumed a healthy appearance, and what had been a large gaping wound capable of admitting all the fingers together, gradually became at the outlet smaller and smaller, till eventually the opening became so closed that there was no possibility of blowing in the iodoform, and so we were obliged to be content with dusting it over the outside. At the same time there was a corresponding improvement in his general condition, and he again surprised the people by once more appearing out of doors.

When his recovery thus seemed really within reach, swelling again took place on each side of his cheek, the pain once more came on, excessive and fetid discharge also made its appearance, and ultimately the wound opened and gaped as much as ever. A medical colleague of age and experience who saw him with me, and has continued to have the charge with myself for the last three months, took it to be malignant from the first day he saw it, and, indeed, had only just before he saw this case attended a patient who had died from apparently the very same thing. I myself, however, still cherished a doubt as to its being cancerous but two months ago, on the occasion of his third relapse, it put on such a strikingly characteristic cancerous appearance that I was almost forced to agree with him. I doubt very much, if any number of medical men had seen it then, that there would have been a single opposite opinion amongst them. His face was greatly swollen, there was hardness on both sides of the lower jaw, all the teeth of this jaw were loose, and his tongue was very red and so swollen as to fill almost the whole of the cavity of the mouth. But this was not all, for on lifting back his head there was seen a large ghastly-looking cavity, discharging offensive matter and shreds of black slough, hanging down from the roof like icicles in a cavern. Then the discharge was so offensive for some time that, clespite the free use of disinfectants, one could hardly stay in the room. Moreover, when we cut off the hanging sloughs on one day, on the next we found fresh ones hanging in the same places.

We now expected a recurrence of the bleeding, and, if there had been, he certainly would not have stond it. Even as it was, the discharge so weakened him that for days he was in a sinking condition, and one night I was sent for, to find him insensible and apparently passing away. His breathing and pulse would hoth stop for many seconds, and once more I never expected him to last till the morning. He did so, however, and, although his revival only seemed a temporary one, he has gradually got better, and so much so, indeed, the last few days, that at the end of another week I should not be at all surprised if he is not downstairs again.

But what is the appearance of the diseased part now Well, this is difficult to describe, and I have never lamented my lack of artistic skill in any case as I have done over this. Unfortunately, too, not only am I myself unable to draw, but I can get no one here who can. The consequence is that only an imperfect description can be supplied, but this I will attempt to give as well as I can. The man's condition now, then, is as follows: His face is almost natural, but, on removing the cloth which encircles his hend and chin, there is exposed a large, clean-looking wound (for the discharge the last few days has become much less in quantity and less offensive in smell), with what appears to be healthy-looking granulations all around. But what is the mischief that has been wrought? Well, nothing more or less than this: 'The whole of the submaxillary space is as clearly exposed as if it had been dissected by a skilled pathologist. There in the centre is the pomum Adami, thyroid cartilage, and hyoid bone, easily felt, and covered only by red granulations; whilst on either side are the submaxillary and sublingual glands, seen as plainly and dissected out as neatly as if it had been done for "Gray's Anatomy." Several medical men have now seen this case, several more have heard of it, but what to call it is an enigma. We want to know the meaning of it. Can any of my readers tell us? I may say that to any specialist interested in it and desirous of inspecting this strange case for themselves, I shall be glad if they will pot themselves in communication with me to direct them how to get here, and to aflord them my hospitality. The case, I believe, is well worth seeing; for every medical man who has seen or heard of it seens to agree in the opinion that it is unique. I will only add tlat there is no history of scrofula or of syphilis; that the patient has been a sailor, I believe, all his life; and seeing that he has not during all the time he has been under treatment taken anything in the way of medicine but a few bottles of iodide of potash mixture, and five grains of calomel on two occasions, the case is very remarkable, and certainly deserves publishing.

Port Isaac, Cornwall.

\section{ON THE}

\section{SURGICAL TREATMENT FOR LACERATIONS OF THE PERINEUM AND THE PELVIC FLOOR. ${ }^{1}$}

BY DR. WM. H. WATHEN,

PROFESSOR OF GYNACOLOGY IX THE KENTCCLY SCHOOL OF MEDICTYE CHAIRMAX OF THE SECTION IN OBSTETRICS AND GYNECOLOGY IN THE AMERICAN MEDICAL ASSOCLATION, ETC.

DR. WhTILN spoke especially of the surgical treatment. of lacerations or injuries of the muscular and aponeurotic. structures that form the floor or diaphragm of the pelvis. He said that there was probably no other subject in gyniccology about which so much had been written that was of no real value, and that a relatively simple operation had been made to appear so complicated that it was seldom correctly performed. He stated that the muscles. and the fascia in the perineum gave it strength, and when they were lacerated no operation that did not primarily tend to reunite them was logical, or would be followed by permanent good results. We might have prolapsus of the uterus, witli rectocele and cystocele, resulting from subcutaneous rupture of these structures, with no laceration or injury of the mucous membrane or other parts of the perineum. This condition was not usually diagnosed by the attending physician, and the woman was subjected to various plans of treatment to hold the parts in position and relieve the annoyance from pressure, weight, \&c, all of which give but little relief; nor could we cure her except by an operation to bring together and reunite the torn ends of the muscles and fascia. For if any of the perineal muscles or the fascia be lacerated, unless at once united and held together, the muscular contractions continued to widen the distance between the torn ends, so that the vulva gradually became enlarged laterally. The extent of this lateral separation was governed by the degree of laceration and the length of time since it occurred. If the above was correct, then no operation would succeed that failed to bring these torn ends together so as to reunite them. This was a simple question that held good in all operations to restore the perineum in complete or incom plete ruptures; and if we were controlled by it, and were familiar with the technique of the operation, success would nearly always crown our efforts. The author did not know of any operation that was not faulty in this particular, but the operations that accomplished this purpose best were those performed by 'Tait, Duncan, Simpson, Langenbeck, Saenger, Hart, and Barbour; yet, if he understood their methods correctly, they did not fully appreciate the importance of dissecting up and uniting the muscles and fascia

An abstrnct of a paper read to the Association of Obstetricians and Gynacologists at the Congress of Physicians and Surgeons, Washing ton, D.C., Sept. 18th, 1888 . 